\title{
Histórias de superação: parto, experiência e emoção
}

Success stories: birth, experience and emotion

Claudia Barcellos Rezende*

*Universidade do Estado do Rio de Janeiro - Rio de Janeiro, RJ, Brasil cbrezende@bighost.com.br

https://orcid.org/0000-0003-0297-1540 


\title{
Resumo
}

Neste artigo, examino as emoções das narrativas de parto de duas gerações de mulheres de camadas médias no Rio de Janeiro. O modo distinto como cada grupo de mulheres conta seus partos aponta para mudanças claras na relação com o sistema de saúde e sugere diferentes percepções de maternidade e subjetividade. Ao mesmo tempo, a análise dos sentimentos expressos nas narrativas revela uma dinâmica emocional semelhante, que dá às histórias um tom de superação e põe em destaque a dimensão da agência. Discuto essas questões com base em entrevistas realizadas com mulheres de camadas médias no Rio de Janeiro, de duas faixas etárias: dos 60 aos 69 anos e dos 37 aos 46 anos. Argumento como o discurso emotivo e, de modo mais amplo, a narrativa da experiência permitem recriar vivencias e articular, por meio deles, diversos temas e valores culturais.

Palavras-chave: narrativas; emoção; parto; gênero.

\begin{abstract}
In this article, I examine the emotions present in birth narratives of two generations of middle class women in Rio de Janeiro. The way in which each group of women recount their births points at marked changes in relations with the Brazilian health system and suggest different perceptions of motherhood and subjectivity. At the same time, the analysis of the emotions expressed in these narratives reveal a similar emotional dynamics, stressing how they overcame difficulties, thus emphasizing their agency. These issues are discussed with reference to material from interviews conducted with middle class women in Rio de Janeiro, of two age groups: between 60 and 69 years old and between 37 and 46 years old. I argue that emotional discourses and, more broadly, narratives of experience recreate how births were lived and articulate various cultural themes and values.
\end{abstract}

Keywords: narratives; emotions; birth; gender. 
A preocupação com a noção de experiência na antropologia desde a década de 1980 revela um interesse na forma como os indivíduos vivenciam aspectos culturais e sociais, formais e institucionalizados. Se a ideia de comportamento remete ao olhar de um observador externo, o conceito de experiência presume um sujeito com agência, que se envolve, interfere e dá sentido à ação em si (Bruner, 1986). Confere destaque à subjetividade, entendida aqui enquanto modos culturalmente constituídos de pensar e sentir que animam os sujeitos em suas ações, levando em conta também as relações de poder nas quais estão inseridos (Ortner, 2007). Inclui não somente a cognição e a consciência, mas também expectativas e emoções, que são, desde Mauss (1981), consideradas um fenômeno individual e social ao mesmo tempo. Ademais, como afirmou Rosaldo (1984, p. 143, tradução minha), "as emoções são pensamentos incorporados" envolvem a pessoa como um todo, enquanto um ser cujo corpo é base de sua vivência do mundo. As emoções e experiência de forma ampla implicam um sujeito em relação com outros, sendo, portanto, intersubjetivas e afetadas por estruturas de poder e contextos socioculturais.

O estudo da experiência requer necessariamente a análise de sua expressão, que é não apenas um meio de manifestá-la, mas também de estruturá-la, como destaca Bruner (1986). Enquanto formas culturalmente e historicamente elaboradas, narrativas, performances, histórias e dramas são unidades organizadas de significados, mobilizadas em situações sociais específicas. Assim, "cada narração é uma imposição arbitrária de sentido no fluxo da memória” (Bruner, 1986, p. 7; tradução minha). Em cada apresentação, rememora-se, revive-se e recria-se a experiência. Na medida em que a experiência envolve sempre os afetos, sua narrativa pode ser vista também como um discurso emotivo. Como argumentaram Abu-Lughod e Lutz (1990), os contextos de expressão das emoções - e, acrescento aqui, a experiência - afetam não apenas seus sentidos como também as relações sociais e a vida social mais ampla, considerando-se sempre a imprevisibilidade nas reações das pessoas em interação. O discurso emotivo e, de modo mais amplo, a narrativa da experiência permitem ver também como se articulam e expressam, por meio deles, diversos temas e valores culturais.

1 Essa afirmação de Rosaldo foi criticada por Abu-Lughod (1990) por subsumir a emoção no polo do pensamento, inadvertidamente replicando a ênfase dada ao mental e cognitivo que caracterizaria as sociedades ocidentais modernas. 
Neste artigo, ${ }^{2}$ analiso as emoções presentes nas narrativas de parto de duas gerações de mulheres de camadas médias no Rio de Janeiro. Considero o parto um fato social total, na acepção de Mauss (1974): é um evento biológico, psicológico e sociológico ao mesmo tempo, envolvendo não só a mulher como também seu ou sua companheiro/a, suas famílias e os profissionais de saúde, que por sua vez agem regulamentados por instâncias governamentais. Nos últimos anos, o parto tem sido objeto de vários estudos nas ciências sociais e tema de discussão mais ampla na sociedade brasileira. Isso se deve em muito à disseminação, desde a década de 1990, dos discursos de humanização do parto, que criticam as altas taxas de cesárea no país, a prática de intervenções médicas rotineiras pouco negociadas com as parturientes e a assimetria entre médico e paciente (Carneiro, 2015; Tornquist, 2004). O modo distinto como os dois grupos de mulheres estudados contam seus partos aponta para mudanças claras na relação com o sistema de saúde e sugere diferentes percepções de maternidade e subjetividade. Em comum às duas gerações, a análise dos sentimentos expressos nas narrativas remete à sua articulação com o corpo e revela uma dinâmica emocional (Coelho, 2010) que dá às histórias um tom de superação e põe em destaque a dimensão da agência.

Examino essas questões com base em entrevistas realizadas com mulheres de camadas médias no Rio de Janeiro, de duas faixas etárias: dos 60 aos 69 anos e dos 37 aos 46 anos. ${ }^{3}$ Entrevistei sete mulheres do primeiro grupo etário e nove do segundo, e as entrevistas tiveram em média 40 minutos, sendo mais longas entre as mulheres mais jovens. Em 2016, quando ouvi suas histórias, as mais jovens haviam tido partos nos três anos anteriores, em um contexto de disseminação dos debates sobre sua humanização. Já a geração mais velha presenciou o início dos grupos de preparação para o parto em princípios da década de 1980, alguns dos quais influenciados pelo movimento do "parto sem dor". As mulheres mais jovens todas estavam casadas, e entre as mais velhas havia duas divorciadas. São todas brancas e têm formação universitária e profissões

2 Uma primeira versão deste trabalho foi apresentada na XII Reunião de Antropologia do Mercosul, em Posadas, Argentina, em 2017. Agradeço a leitura e os comentários de Maria Claudia Coelho, Rachel Aisengart Menezes, Waleska Aureliano e Romário Nelvo.

3 Os dados analisados aqui resultam do projeto de pesquisa "Histórias de parto: pessoa e parentesco", apoiado pelo Programa Pro-Ciência da Uerj e pelo CNPq (Bolsa de Produtividade). 
como médica, psicóloga, arquiteta, musicista, professora universitária. Dessas mulheres, algumas tiverem partos normais, outras fizeram cesáreas, mas todas desejaram a gravidez e entraram em trabalho de parto. As mais velhas tiveram em média três filhos e as mais novas, dois. Todas fizeram seus partos no sistema privado de saúde do Brasil.

Todas as narrativas foram contadas para mim, pesquisadora que era em alguns casos parente, amiga ou conhecida de amiga, de geração intermediária às duas pesquisadas. Sou também mãe, fato sabido pela maioria e que afetou o quanto descreviam seus partos. ${ }^{4}$ Conversamos em suas casas, na maioria das vezes com a presença de filhos pequenos, mas também em cafés e outros espaços públicos. A diferença de local não afetou o quão detalhado eram os relatos nem o tipo de informação dada. Como leram e assinaram um termo de consentimento livre, essas mulheres tiveram uma apresentação breve aos objetivos da pesquisa. Comecei todas as conversas perguntando sobre as gestações para então chegar aos partos. Entre as mais velhas, chamou atenção a dimensão comparativa da pesquisa, o que produziu comentários sobre como as coisas eram no passado em comparação ao presente. Entre as mais novas, foi constante a referência aos discursos do parto humanizado, mesmo que não mencionados no termo de consentimento. Portanto, as histórias de parto que analiso foram contadas em uma relação intersubjetiva específica, em um tempo e local particulares.

\section{Narrativas em pesquisas na saúde}

Estudar a experiência através da narrativa implica estar atento a uma estrutura discursiva específica, sujeita a formas de composição articuladas à temporalidade (Arfuch, 2010; Riessman, 1993). São também meios de destacar o narrador e, portanto, questões em torno de sua agência e subjetividade, sem deixar de fora o contexto social e histórico no qual está inserido (Maynes; Pierce; Laslett, 2008). Como aponta Riessman (1993), ainda que a definição específica de narrativa possa variar, existem certos elementos estruturais que lhe dão forma.

4 Nas entrevistas com mulheres jovens sobre seus partos feitas por um aluno meu, o detalhamento da descrição do parto, mesmo quando cesárea, foi bem maior do que nos relatos contados para mim. 
Em uma narrativa "completa", há um resumo da história, sua localização (tempo, lugar, situação, participantes), o desenrolar dos eventos, sua avaliação, sua resolução e uma coda - um retorno ao presente do narrador (Riessman, 1993, p. 18). Assim, o estudo desses aspectos formais permite entender como elas são contadas, suas ênfases e ausências, indo além do conteúdo do que é dito.

Nos eventos de saúde e doença, as narrativas constituem leituras e lugares possíveis para essas experiências, que podem afetar a percepção corporal e levar a uma ruptura biográfica mudando a relação do sujeito com o mundo (Aureliano, 2012). Se a doença é uma experiência que desorganiza a atitude natural diante do mundo, o ato de narrá-la oferece um meio de dar significado à experiência e reordená-la (Rabelo et al., 1999). O parto, mesmo não constituindo uma doença, afeta a relação das mulheres com seu corpo, sua subjetividade e suas relações sociais, de maneira que suas histórias dão sentido a essas mudanças.

No contexto social pesquisado, o corpo é visto predominantemente a partir da perspectiva de sua medicalização, entendida como uma associação de regimes de verdade, estratégias de intervenção e modos de subjetivação (Foucault, 1997; Rabinow; Rose, 2006). Desde o século passado, a gravidez e o parto têm sido tratados como eventos médicos, devendo ser monitorados por profissionais da saúde, testes laboratoriais e exames de ultrassonografia, e vivenciados em hospitais (Chazan, 2007; Rohden, 2001; Tornquist, 2004). Essa visão medicalizada da gestação e do parto se mantém mesmo nos discursos de humanização do parto. Assim, as narrativas de parto analisadas aqui oferecem também uma compreensão da experiência desse sistema médico, mostrando como as mulheres negociam sentidos de práticas e diagnósticos ao longo de suas gestações e partos. São distintas do evento em si, tal qual vivenciado, articulando biografias a significados culturais de pessoa, corpo, gênero e maternidade.

Se esses temas se revelam nas histórias contadas, há nelas também marcas nítidas de geração e classe. Martins (2005) estudou as memórias de mulheres de camadas trabalhadoras que tiveram filhos nas décadas de 1940 e 1950 em Curitiba. Suas histórias são marcadas por silêncios e reticências, nas quais gravidez e parto são contados de forma rápida, sem detalhes. A maioria sintetizava suas experiências nos primeiros partos. "Para elas a gravidez e os partos não são acontecimentos marcantes, emocionalmente intensos ou traumáticos, para que sejam organizados detalhadamente na narrativa" (Martins, 2005, p. 68). Longe de ver essa economia de frases como um sinal de esquecimento, 
Martins argumenta que esse traço narrativo pode ser visto como uma característica de geração para quem a maternidade era mais uma atribuição que as mulheres desempenhavam, assim como o trabalho doméstico.

Almeida (1987), por sua vez, entrevistou mulheres de camadas médias no Rio de Janeiro que tiveram filhos na década de 1950. Nos relatos delas, o parto adquire maior relevância, se comparado à gravidez, pouco pontuada e comentada de forma passageira. As sensações dramáticas do parto, em particular a dor da contração e o tempo em trabalho de parto, separavam as condições de "mulher" e "mãe". Em outros momentos dos depoimentos, o foco estava nas tarefas que desempenhavam como parte do ato materno, um exercício "fundamentalmente técnico, sendo raras as menções aos aspectos emocionais e psicológicos implicados nesta experiência" (Almeida, 1987, p. 51). Assim como as mulheres estudadas por Martins, aqui também a maternidade era exercida de acordo com um código já estabelecido, não sendo o sujeito um eixo de orientação.

As histórias de parto que ouvi são distintas dos relatos examinados por Martins e Almeida, revelando mudanças nas práticas médicas, nas relações de gênero e de conjugalidade. Entre as mais velhas, as primeiras gestações foram desejadas, mas muitas vezes não planejadas, acontecendo quando tinham vinte e poucos anos e eram recém-casadas. O marido esteve presente no hospital, porém muitos não presenciaram o nascimento dos filhos. Todas manifestaram desejo de parto normal e algumas se prepararam indo para grupos de gestantes que começavam a aparecer no Rio de Janeiro, ou através de livros. A relação com o médico era mais assimétrica, de tal modo que muitas tiveram experiências complicadas, com mudanças frequentes no tipo de parto, por conta de decisões do obstetra que não foram discutidas com elas. Assim, o uso de indução através de ocitocina sintética, a administração de anestesia geral e o recurso a fórceps ou extrator a vácuo foram medidas criticadas e que levaram muitas a mudar de obstetra na gestação seguinte. Por fim, o bebê cujo sexo era desconhecido pela maioria, que não fez ultrassonografia obstétrica, torna-se nomeado e "conhecido" somente após o parto.

Nas narrativas das mulheres mais jovens, há um planejamento detalhado da gravidez e do parto desejado. Para tanto, buscaram informações em livros e sites de internet ou em grupos de gestante e os obstetras recomendados por parentes e amigos. A disseminação dos discursos e práticas do parto humanizado permeiam seus relatos e várias tiveram partos com médicos adeptos desse 
ideário - partos normais, alguns sem anestesia, sem episiotomia, nos quais tudo era conversado e negociado com elas. Os maridos participaram de todo esse processo e foram extremamente atuantes também durante o parto. Todas tiveram o parto que escolheram - algumas fizeram cesárea na primeira gravidez e depois realizaram parto normal. As dificuldades ou problemas apontados surgiram em relação ao comportamento médico ou à equipe de profissionais do hospital. Com exceção de uma entrevistada que optou por não ser informada sobre o sexo do bebê, todas já sabiam se esperavam menino ou menina e se referiam a eles ao longo das narrativas pelo nome escolhido desde o início da gestação.

\section{Duas narrativas sobre parto}

As narrativas de Vera, Márcia, Letícia e Daniela, que apresento a seguir, ilustram essas questões e diferenças. Contudo, minha análise se deterá no modo distinto como as mulheres dos dois grupos etários narraram seus partos. Com exceção de duas mulheres mais jovens, todas as outras, de ambas as faixas etárias, tiveram mais de um filho e contaram cada um de seus partos comparando-os entre si. Entre as mais velhas, havia também uma comparação entre a época dos seus partos e o presente, observado através dos partos das filhas e/ ou noras.

Essas narrativas foram selecionadas por apresentarem de forma nítida os aspectos formais da narrativa discutidos por Riessman (1993): um resumo da história, sua localização (tempo, lugar, situação, participantes), o desenrolar dos eventos, sua avaliação e sua resolução. Idealmente, seria interessante expor aqui os trechos sem edição minha, mas diante da extensão dos relatos, trago uma versão abreviada deles. ${ }^{5}$

Vera, professora aposentada e empresária, tinha 68 anos quando entrevistada em sua casa e narrou seu primeiro parto, aos 21 anos:

5 Uso colchetes e reticências [...] para indicar trechos suprimidos, todos eles com repetição de falas e expressões como "tipo assim", "sabe". A sequência de ideias não foi alterada. Os nomes e outros elementos biográficos foram modificados para preservar o anonimato das entrevistadas. 
Quando eu fiz nove meses de casada eu entrei em trabalho de parto. Foi uma gravidez desejada, dentro do contexto era o normal, e eu comprei livros que falavam de parto sem dor, me preparei... pra um parto natural, que pra mim era o único aceitável. No dia em que eu entrei em trabalho de parto, foi dia 31 de dezembro pela manhã, liguei pra casa do meu médico, a empregada atendeu e me disse que ele tava esquiando lá no Rio São Francisco. Aí eu falei: “Como é que eu posso encontrar ele?" "Ah, só se a senhora pegar um barco e ir lá”, então fomos pra um hospital - foi interessante - fomos pra um primeiro hospital que era perto lá de casa, não tinha vaga na maternidade. [...] fomos para outro, também não tinha vaga, e aí fomos pra um hospital que na época era meio fora do centro [...], que não era nem maternidade. Chegando lá, a enfermeira me examinou - isso eram 11 horas da manhã do dia 31 - porque eu fiquei contando tempo de contração, eu demorei pra acordar Marcos, porque eu sabia que tava tudo bem, e aí quando a enfermeira examinou lá ela falou: "Não, o bebê tá sentado e precisa ser cesariana." Aí via telefone não conseguiu nenhum médico [...], enfim, veio um médico que era o único que estaria disponível, que eu não conhecia, quando ele fez o toque, ele: "Tá sentado e é uma criança muito grande, tem que ser cesariana." Na hora eu falei pra ele: "Eu não quero cesariana" [enfática], ele foi bem esperto, se afastou um pouco e falou: “Bem, a decisão é sua, eu só queria esclarecer que nesse caso, uma criança grande, o cordão pode enrolar no pescoço e tudo, ele tem duas possibilidades em dez de sobreviver"... "Não, então eu quero cesariana" [enfática], aí foi uma correria pra as pessoas mesmo, os amigos, irem buscar o anestesista, o pessoal da equipe em casa, porque já tava com trabalho de parto bem avançado, e preparar a sala e tudo. E foi cesariana, eu lembro que me deram uma anestesia raquidiana, eu dormi, não vi nada, tempos depois eu acordei, me falaram que era um menino, me levaram pro quarto... e quando eu acordei, eu soube que meu filho se chamava Renato [risos]. Durante a gravidez eu fiz várias tentativas de escolher nome e Marcos dizia que quando nascesse a gente via, mas um dos que eu tinha sugerido desde o início era Renato [...] E aí nasceu Renato. [Pergunto: “Na sala de parto, Marcos assistiu?"] Não, ninguém assistiu. Inclusive, quando a enfermeira falou pro Marcos e pra minha tia: "Vai ser cesariana”, ela disse: "Não, ela não quer cesariana", porque todo mundo sabia que eu não queria cesariana e até que eu não queria aquele médico, que tinham me falado que ele era muito grosseiro e tal. Nem foi, foi esperto ele. Então foi tumultuado isso, longe de ser tranquilo. Desde o lugar do hospital a tudo. Tudo fora do que a gente tinha planejado. 
Apresento a seguir o relato de Letícia, socióloga com 38 anos, sobre seu primeiro parto quatro anos antes do nosso encontro em um café:

Aí fez 40 semanas [...] e no dia que ela nasceu, ela nasceu dia 3 de novembro [...] a gente foi no cinema [...] aí cheguei em casa, deitei, a gente chegou $9 \mathrm{~h} 30$ - nunca esqueço isso - a gente deitou umas dez e pouco. $11 \mathrm{~h} 30$ começaram as contrações, claramente [...] Aí eu liguei para o Roberto [obstetra], ele tinha acabado de chegar em casa [...] tinha chegado de um parto que tinha durado 24 horas e virou um cesárea de emergência. Ele estava exausto! Aí ele: "Espera aí [...] dorme aí, fica aí em casa, me liga daqui a uma hora." [...] Quando deu duas e meia, eu falei: "Pietro, não vai rolar, eu não vou ficar em casa." Ah, eu tinha todo um discurso, inclusive com ele, de que eu ia ficar em casa a maior parte do trabalho de parto [...], mas aí eu comecei a amarelar [risos] [...] eu já tava com muita dor, Pietro falou: "Cara, a gente tá indo"... a gente saiu de casa às $3 \mathrm{~h} 30 . .$. ele foi superdevagar, né, porque doía minha barriga, a gente chegou às quatro, demoramos meia hora pra chegar [...] O Roberto chegou 4h20. Foi impecável nesse aspecto. Aí eu tinha uma doula também, que era uma menina muito legal [...] A Renata também veio de Jacarepaguá, chegou às cinco, foi maravilhoso. Era uma suíte, o Roberto ficou dormindo na sala do lado, e eu fiquei em trabalho de parto com o Pietro e a doula. E o combinado com a doula... meu marido teve ciúme da doula no fim da gestação, ele falou: "Eu não quero que ela participe do parto" "Cara, mas eu quero que tenha doula, então vamo chegar a um acordo", e aí ele sugeriu: "Ela participa, mas eu sou o protagonista." Foi incrível! Ela ficava assessorando ele e ele é que fazia o trabalho dela que era massagem ou então me segurar. [...] Eu acho que o parto é uma produção coletiva. Eu consegui manter a presença dela que me acalmava, mas ela não foi a... ele que... eu era a protagonista na verdade [risos] [...] Aí as contrações começaram a apertar e aí teve um comentário de uma enfermeira que foi horrível... eu tava urrando de dor [...]: "Olha você tá reclamando agora, parir não é difícil, difícil é amamentar." Foi horrível o comentário, mas ao mesmo tempo eu acho que ela tem toda a razão! Parir é mais fácil do que amamentar na minha experiência [...] aí foi isso, eu tava em trabalho de parto desde 11h30, né, já eram 6h30, aí o Roberto chegou, viu, falou vamos descer pra sala de parto humanizado [...] E lá foi ruim, o tempo todo que eu tava no quarto, eu tava me sentindo muito bem... Na sala de parto humanizado, eu não achei lugar pra eu ficar... eu queria contato com o chão [...] aí eu fui pro banheirinho, fiquei agachada lá do lado da 
banheira, o tempo todo, e aí eu já tava com oito, sete pra oito de dilatação, aí eu tinha combinado comigo e com o obstetra: "Eu não quero anestesia, salvo se a dor virar tortura" [...] Aí quando deu oito de dilatação, eu achei que fosse morrer... aí eu falei pra ele: "Oh, agora eu quero" [risos]. Aí veio o anestesista, que é um capítulo à parte, um cara incrível, chamado Tião, [...] que chegou com uma energia maravilhosa, e é na verdade uma analgesia... Que que aconteceu? Eu continuei sentindo muita dor, mas assim suportável [...] No segundo parto eu entendi que que é ter um parto realmente com anestesia. [...] Então foi incrível que nessa hora, entre oito e dez de dilatação, eu respirei, eu bebi água, eu comi um negócio, que eles já tavam vendo que não ia virar cesárea, me recobrei, conversei com a Sofia, ficava cantando pra ela descer, então foi um momento muito incrível dessa analgesia assim. Isso é humanizado... tipo parto sem anestesia é animalizado! [risos] [...] aí chegou a hora de fazer força, eu tava bem cansada mas eu tive força, que teve um momento que o Pedro [pediatra] falou: "Agora vai ter que ser, que agora já não tá ficando legal pra ela", eu gelei né, mas aí foi incrível, emoção total, na verdade, na hora que nasceu, eu só conseguia sentir alivio [risos], Pietro chorando, todo mundo emocionado e eu falei: "Gente, sou só tou aliviada" [risos] essa coisa da emoção foi na hora que eu amamentei, aí eu chorei, desabei... e eu acho que o pediatra foi maravilhoso também, porque o Roberto tava de mau humor. [...] E ele me pôs na posição certa, ele me acalmou, me deu muita força na hora de fazer a contração, e aí também esse é um trabalho de equipe. E aí nasceu a Sofia...

As narrativas de Vera e Letícia são singulares, como são as demais e também os relatos de seus outros partos. Há nelas elementos comuns e diferenças geracionais significativas, que examino aqui os tomando como exemplos de aspectos presentes nas histórias das outras mulheres. Procuro nesta análise menos os conteúdos expressos do que os sentidos entrevistos pelo exame da forma narrativa.

Em comum, Vera e Letícia começam localizando no tempo e no espaço o início do trabalho de parto. Ambas estavam em casa e mencionam o dia do mês e a hora do dia em que sentiram as primeiras contrações. Em seguida, apresentam os participantes - maridos, obstetras, amigos, tias, doulas, equipe do hospital, apontando como cada um se comportou. Uma ação-chave é o marido ligar para o obstetra e levar sua mulher para o hospital. Contam sobre a ida para o hospital - Vera buscando um hospital que pudesse a acolher, Letícia sobre 
a lentidão da viagem. Apontam eventos ou momentos complicadores - Vera por não encontrar seu médico nem vaga nos hospitais e Letícia por deparar-se com a exaustão do seu, ouvir um comentário horrível da enfermeira e mudar de quarto no processo do parto. No hospital, relatam as interações com médicos e enfermeiras, falam do parto em si e terminam com o nascimento do filho. Em ambas as histórias, há uma avaliação da experiência - a intensidade das dificuldades para Vera e a emoção total para Letícia. Ainda que todas as mulheres tenham discorrido um pouco sobre os primeiros dias seguintes, o momento em que veem o filho encerra o parto. Ambas usam as mesmas palavras "e aí nasceu Renato/Sofia".

Assim, há nas duas as referências ao tempo e espaço em que transcorre a ação - o parto - bem como às pessoas que participam dela - elas próprias, seus maridos, médicos e enfermeiras. Ressalto que nas duas histórias, os pais do casal estão ausentes, mas outras figuras como a tia e os amigos de Vera e a doula de Letícia entram em cena. Nos dois relatos, o bebê aparece pouco - uma vez durante o parto e ao nascerem. Ambas destacam também as dificuldades e impasses surgidos e como afetaram o desenrolar do evento, qualificando-o ao final.

Se essa estrutura narrativa está presente em todos os relatos de parto que escutei, há diferenças importantes entre as duas gerações de mulheres, além é claro das particularidades de cada história. Primeiro, chamo atenção para a extensão do depoimento de Letícia, apresentado aqui de forma abreviada. As narrativas das mulheres mais jovens foram todas mais longas e detalhadas do que as das mulheres mais velhas. Letícia relembra o que tinha feito antes de entrar no trabalho de parto, o que pensou, os diálogos com o médico, seu humor, a relação com o espaço e profissionais no hospital, a sensação da dor antes e depois da analgesia, além de inserir ao longo outros comentários - sobre a relação entre seu marido e a doula, sobre amamentação e sobre anestesia e parto humanizado. Essa diferença pode ser atribuída em parte ao fato de que elas tiveram partos recentes e por isso lembram-se de mais detalhes. Contudo, como argumentam Halbwachs (1990) e Bruner (1986), o ato de rememorar é também afetado pelo presente e pelas ordens de relevância. Assim, vejo também no detalhamento maior das mais jovens uma importância dada àquele evento, distinto do que foi para as mais velhas, como desenvolvo a seguir.

A participação de outras pessoas no parto também é descrita de forma distinta. Vera menciona o marido no início e no final, faz referência a vários 
obstetras, mas não nomeia nenhum deles. Da equipe médica que realiza o parto, há uma breve menção sobre o anestesista, que teve que ser chamado às pressas para o hospital, e o diálogo com o obstetra sobre o tipo de parto. Letícia, por sua vez, refere-se à maioria dos participantes pelo nome, descrevendo-os também em termos de suas qualidades. Seu marido aparece várias vezes ao longo do relato - desde o início do trabalho de parto, o telefonema para o médico, a ida para o hospital, a participação no parto, à emoção com o nascimento do filho. Seu obstetra figura igualmente de forma detalhada, em termos do que falou em vários momentos e do seu estado de espírito e humor ao longo do processo.

Além de formas de participação diversas, há personagens diferentes nas histórias. No parto de Vera, os amigos tiveram uma atuação importante, pois se mobilizaram para encontrar um obstetra disponível e depois, com a definição da cesárea, chamar um anestesista. Sua tia estava presente também e tentou intermediar a negociação do parto. No parto de Letícia, é a doula a pessoa que ampara e acalma. As doulas se tornaram figuras importantes na gestação e parto nos últimos anos (Carneiro, 2015; Simas, 2016), estando, portanto, ausentes nos partos de mulheres mais velhas como Vera.

O modo como o bebê aparece nos relatos também é distinto. Na história de Vera, o bebê surge de forma vaga - "a criança" - antes de nascer. A única característica mencionada é seu tamanho grande, que justifica a cesárea de acordo com o médico. Seu nome é dado após o parto, quando se descobre que é um menino. Ainda que algumas opções tivessem sido discutidas durante a gravidez, Vera não participa da escolha final do nome por estar desacordada. O bebê de Letícia já tinha nome, prática comum decorrente do uso rotineiro de ultrassonografias obstétricas no pré-natal desde a década de 1980 (Chazan, 2007). Ele aparece como pessoa também por ser parte de uma conversa, e para quem ela canta.

Os elementos dramáticos das narrativas são também diferentes. Se em ambas há imprevistos, eles são de ordens diferentes. O desenrolar do parto de Vera é marcado por dificuldades - o trabalho de parto na véspera de Ano Novo, a dificuldade de achar médico disponível e vaga no hospital, a mudança do tipo de parto e a sua exclusão na decisão sobre o nome do bebê. Ressalto que nas narrativas das mulheres mais velhas, foi recorrente a presença de imprevistos semelhantes, ao passo que entre as mulheres mais jovens, eles estão quase ausentes. Os aspectos inesperados na história de Letícia referem-se a sentimentos seus e de alguns atores. Seu obstetra estava exausto e de mau humor, 
mas mesmo assim ele foi "impecável". Ela gostaria de ter ficado em casa o maior tempo possível de seu trabalho de parto, mas "amarelou". Sentiu dificuldade de conectar-se com o espaço do centro cirúrgico e ouviu o comentário "horrível” da enfermeira sobre a dor de parir e de amamentar, porém nenhuma dessas sensações interferiu no desenrolar e no desfecho do parto. Como outras mulheres mais jovens, há relatos de pequenos conflitos de negociação com a equipe médica e profissionais do hospital, que não chegam, contudo, a mudar o tipo de parto nem o seu final.

\section{As emoções nas narrativas}

Uma distinção importante nas narrativas de Vera e Letícia está na forma como cada uma conta emocionalmente sua experiência. Vera falou de suas dificuldades, contando os percalços com ironia e avaliando sua experiência somente ao final. Ao passo que Letícia usou adjetivos com frequência para qualificar tudo o que aconteceu, além de falar de suas emoções e sensações corporais ao longo do parto.

Como os outros aspectos mencionados anteriormente, essa diferença se apresenta também em outros relatos e está relacionada, na minha visão, a modos distintos de vivenciar o parto. Para desenvolver essa questão, apresento dois trechos das narrativas de Márcia, 63 anos, e Daniela, 38 anos. Embora suas experiências contrastem com as de Vera e Letícia, a forma de suas narrativas é semelhante. Márcia, que era médica homeopata, havia tido seu primeiro filho de cesárea. Mudou de obstetra para ter seu segundo filho por parto normal. Entrevistada em sua casa, ela conta:

Aí chegou num determinado dia [...] eu tinha um exame marcado para ver contração uterina porque o médico me pediu alguns exames quando foi chegando perto do parto, pra ele ter noção por causa da ideia do parto normal. Aí eu fui fazer o exame e o médico disse assim: "Você não tá sentido nada?" "Eu tô sentindo um pouco de cólica." Aí ele disse assim: "Você está em trabalho de parto!" Mas eu tava muito calma. Daí ele disse: "Daqui você vai pro hospital." Eu disse: "Não, daqui eu vou ver as coisas em casa, arrumar a mala" [...] Aí eu fui pra casa, liguei pro meu marido que estava no escritório, tudo isso eu tava dirigindo. Meu marido disse: "Então tá, eu te encontro na clínica", eu disse: "Não, agora 
você vai dirigir." E aí fomos pra clínica, eu tava em trabalho de parto mesmo, o começo muito tranquilo, eu sei que entrei na clínica era umas sete e pouco da noite, minha filha nasceu às dez da noite, foi parto normal, mas o médico botou [...] um aparelho que nem existe mais, cheio de fios assim, porque ele queria ver batimento cardíaco do bebê, queria ver... sim, porque no ultrassom tinha dado que talvez ela tivesse circular de cordão [...] Ela não tinha circular de cordão, tinha uma alça, um cordão do lado da cabeça, então ele tava preocupado na hora da passagem e também pra ver a contração uterina [...] E entrei em trabalho de parto, fiquei no quarto... que tem uma coisa engraçada naquela época. Os médicos entraram pra me examinar todos fumando no quarto [risos] [...] Bom, e aí foi indo o trabalho de parto, aumentado as contrações, diminuindo o intervalo, chegou um certo momento assim foi rápido, de sete e pouco e ela nascer às dez, foi bem rápido. E foi muito bom! Aí o assistente cortou o cordão umbilical, o médico botou ela aqui em cima de mim no peito e eu fiquei muito feliz. Agora como foi um trabalho de parto que foi tudo muito bem, teve um detalhe. O médico perguntou se o filho dele que era estudante de medicina podia assistir. Eu disse que podia. Dali a mais um pouco o médico disse: "Ah, tem não sei quem ..., pode assistir também?" “Pode". Daqui a pouco eu disse assim: "Você tá chamando todo mundo assim?" Fiquei tensa no final por causa da dor das contrações, né, mas o pediatra, meu pediatra chegou também... enfim, aí foi assim, foi muito bom!

Daniela, que era economista, teve seus dois filhos de parto normal, mas considerou seu primeiro parto difícil. Seu obstetra viajou no final da sua gestação, e quando ela entrou em trabalho de parto, teve que recorrer à médica substituta, adepta do parto vaginal natural. ${ }^{6}$ Dada a extensão do seu relato, feito em sua casa com a presença intermitente dos filhos, cito a partir do momento em que ela vai para o hospital, depois de três dias com um pequeno rompimento da bolsa d'água:

[Cheguei] umas dez horas da manhã [do sábado], ela chegou pra me examinar uma hora da tarde. Aí ela falou assim: "Olha Daniela, a gente tem duas opções:

6 O parto vaginal natural é aquele em que o obstetra não faz nenhuma intervenção no corpo da parturiente - sem indução de contração, sem uso de anestesia ou analgesia, sem o corte do períneo. 
[...] assim 48 horas é o máximo que a gente pode aguardar, só que tem um problema. Se a gente esperar 48 horas e der um exame de sangue com alguma bactéria, eu vou ter que partir pra cesárea [...] Ou a gente pode induzir hoje e vamos ver." Eu achei assim válido tentar induzir, porque eu queria muito o parto normal e tal [...] Aí começou a ocitocina. Aí é brabo! É muito diferente um parto do outro, porque o segundo foi mais redondinho. Mas a ocitocina sintética começou a doer muito, e assim em intervalos curtos. Eu mal me recuperava e já começava a sentir... e aí meia-noite liberaram o quarto humanizado. Uma coisa que eu achei muito ruim do hospital: queriam que eu fosse de maca. Eu falei: "Gente, eu posso andar", porque quando eu tava em contração, a pior coisa pra mim era ficar parada, deitada [...] Aí já foi uma coisa meio chata... chega no quarto você tem que botar touca, tem que botar negocinho no pé, camisola... E aí eu sabia que no primeiro parto, se doesse muito, eu ia pedir anestesia... Uma e meia eu falei: "Ai doutora, eu quero anestesia, eu não tô aguentando." Eu achei muito ruim porque ela não queria [...] eu não tinha um vínculo com ela, sabe, eu tinha um vínculo com o outro médico [...] nessa hora quebrou muito minha confiança com ela, eu não sentia mais firmeza que eu podia contar com ela, sabe, e aí eu sei que, depois de eu muito insistir, ela ligou pro anestesista. Só que ainda ia demorar, e aí a enfermeira [obstétrica] e o meu marido falaram pra eu ir pra banheira, que lá no quarto humanizado tem [...] aí fui e foi ótimo porque eu relaxei bastante e dilatei tudo [...] eu sei que eu tava muito cansada e eu não sei se foi a analgesia, mas eu tive muita dificuldade pra fazer força [...] ela me colocava numa postura lá pra eu fazer a força e eu fazia a força máxima pra mim possível, mas não era suficiente. E ela começou a me criticar, falando que eu não tava fazendo certo, e aí eu fui começando a ficar meio rebelde, sabe [risos] [...] Eu acho que eu fiquei nervosa, acho que a equipe toda se perdeu, sabe... só que a Roberta é a médica, chega uma hora que o médico tem que... ela tem muita responsabilidade na mão dela. E ela falou assim: "Você quer fazer cesárea?" Eu falei: “Eu quero!" [risos]. Eu não sabia o que fazer, eu queria ter, mas do jeito que eu tava tentando, eu não tava conseguindo, então faz cesárea, tem que sair de algum jeito [...] E a gente foi pro centro cirúrgico, aí tinha que ficar deitada e eu não deitava. Eu sei que teve que amarrar minha perna, então foi muito... dramático, foi um parto difícil, e aí teve que fazer episio, ela me pediu desculpas porque ela não costuma fazer episio... E aí o médico fez aquela manobra do Kristeller pra poder sair. A primeira vez eu levantei, sei lá, eu me mexi, não foi. A segunda, "deixa”, eu deixei, aí nasceu, sabe? 
As narrativas de Márcia e Daniela mantêm a mesma estrutura formal dos relatos de Vera e Letícia, analisados acima. Há a ordenação temporal e a localização do evento, a referência aos participantes, sempre com destaque dado para a equipe médica, os momentos tensos e a resolução. As diferenças geracionais também estão presentes, em particular o contraste na extensão e detalhamento dos relatos. Se a experiência de Vera foi "complicada", a de Márcia foi "muito boa". Já o parto de Daniela foi muito "dramático" se comparado ao de Letícia, que foi "emoção total".

Na história de Márcia, assim como na de Vera, o tom é mais descritivo e são poucos os adjetivos usados. Há uma perspectiva comparativa, tanto em relação a mudanças de comportamento "naquela época" quanto em referência a seu parto anterior, que se tornou uma cesárea que não gostou. Três sentimentos aparecem na seguinte ordem: a tranquilidade durante o trabalho de parto, a satisfação e felicidade depois que nasce a filha e a tensão por conta da dor das contrações. Vera também comentou que se sentia bem no início do trabalho de parto, mas afirmou como foi "tumultuado" para ela, somente ao final. Nenhuma delas se detém nas suas sensações corporais. Vera comenta apenas que no início do trabalho de parto monitorava o intervalo entre as contrações e que estava "tudo bem". Márcia não sentiu que estava em trabalho de parto, falou do tempo cada vez menor entre as contrações e só disse ter sentido dor ao final do relato.

As narrativas de Daniela e Letícia, ao contrário, são ricas em adjetivos que qualificam afetivamente pessoas e momentos da história. Se Letícia enalteceu a "energia maravilhosa" da maioria da equipe médica, Daniela destacou os aspectos que foram "ruins" ou "chatos". Igualmente presente em ambas é uma diversidade maior de emoções e sensações experimentadas. Letícia sente medo de esperar mais para ir ao hospital, é afetada pelo comentário da enfermeira, é acalmada pela doula, sente dor e acha que vai morrer, se recobra com a anestesia, fica cansada, "gela" com o alerta do pediatra, sente alívio no final e emoção total ao amamentar. Daniela começa o trabalho de parto tranquila, sente muita dor por conta da indução, fica cansada com as contrações, perde confiança na médica, fica nervosa e rebelde e tem dificuldade de fazer força ao final. Considerou seu parto dramático e não queria que seu filho, que entrava e saía da sala durante a entrevista, escutasse sua história.

A presença da dor nos relatos é outro elemento diferenciador das narrativas. Sarti (2001) lembra que a experiência da dor é ao mesmo tempo física 
e subjetiva, individual e social. É ao mesmo tempo uma sensação corporal e uma emoção. Nos relatos das mulheres mais velhas, a dor aparece pouco, com frequência nos casos em que o parto foi induzido com ocitocina sintética. Já as mais jovens falam da dor intensa nos momentos finais do trabalho de parto, particularmente quando nascem os primeiros filhos. Entre elas, a referência à dor aparece quase sempre associada a negociações a serem feitas - algumas têm que lidar com seu desejo inicial de não tomar anestesia, outras precisam negociar com a equipe médica a aplicação da analgesia ou quando fazê-la, avaliando seu limiar de dor. Nesses casos, a dor aparece de forma ambivalente - esperada, mas não tanto, afetando também um ideal de parto vaginal natural que se tornou mais difundido nesse meio social (Carneiro, 2015; Hirsch, 2015).

A relação com médicos e outros profissionais no hospital é outro foco produtor de tensão, desde um comentário que desagrada, regras que atrapalham, ao modo como o obstetra e sua equipe se comportam durante o parto. Como sugerem Carson et al. (2017), é no hospital, especialmente na sala de parto, que a mulher se torna mãe sob o olhar público, recebendo crítica ou apoio dos profissionais e familiares presentes. O subtexto das narrativas de parto é, segundo estes autores, a história das coisas que não se pode controlar. As mulheres mais velhas relataram ter sido submetidas mais vezes às decisões dos médicos com pouca ou nenhuma discussão. Embora tenham nessas situações procurado outros médicos nas gestações seguintes, esses episódios foram contados com poucas emoções, como se aquela relação assimétrica fosse esperada. Entre as mais jovens, a narrativa de muitas interações no hospital que não aconteciam como elas esperavam vinha acompanhada de sentimentos e avaliações, ${ }^{7}$ como se houvesse uma idealização do desenrolar do parto tomada como medida da experiência.

Apesar dessas distinções, há em comum um relato do parto como experiência ao mesmo tempo física e emocional. Ainda que com elaborações variadas, Vera, Márcia, Daniela e Letícia recorrem em suas histórias a categorias que se referem a emoções e a sensações corporais ao mesmo tempo. Os termos dor e alivio falam ora de algo sentido no corpo, ou vivido como sentimento, ou de um

7 Em outro artigo (Rezende, 2017) discuto como essas diferenças geracionais se manifestam no modo de destacar ou não a importância de confiar no obstetra. 
estado que é concomitantemente físico e emotivo. ${ }^{8}$ Apesar dessa ambiguidade, a relação entre emoção e corpo aparece reforçada, como uma experiência que é sempre incorporada (Abu-Lughod; Lutz, 1990; Rosaldo, 1984). Ao mesmo tempo, o parto coloca-se como evento fisiológico que é vivido emocionalmente também, mostrando a ressonância afetiva desse acontecimento (Le Breton, 2009) para essas mulheres.

A dinâmica emocional nas quatro narrativas também é semelhante. Todas relatam uma calma inicial, mesmo no primeiro parto. Há uma tensão durante o trabalho de parto, que pode se referir a diversos aspectos, como a sensação da dor. O desfecho do parto traz alívio, ao mesmo tempo em que efetiva uma mudança: o nascimento do filho. É também o momento emocional que diferencia os relatos: a satisfação e emoção de Márcia e Letícia em contraste com o tumulto e o drama de Vera e Daniela. À semelhança do complexo de sentimentos narrados por vítimas de violência analisado por Coelho (2010), que realiza o "trabalho" de restaurar simbolicamente uma hierarquia rompida, nas histórias de parto a recorrência das emoções expressas apresenta uma dinâmica emocional cuja lógica está na superação - das dores, dos imprevistos, das negociações e imposições médicas.

\section{Considerações finais}

A análise da estrutura de uma narrativa pessoal revela não apenas questões em torno da experiência, como uma construção subjetiva, as emoções e a agência envolvidas, bem como temas mais amplos da vida social. Contar o parto é uma prática social comum em muitas sociedades, como apontam Carson et al. (2017). Em sua pesquisa, analisam como as narrativas de adolescentes no Canadá sobre seus partos contribuem para a formação de suas identidades como mãe. O modo como falam da dor do parto com humor ou estoicismo é visto como meio de manter controle de si nas narrativas. Em um meio no qual é normal que o parto aconteça sem anestesia, as jovens relatavam suportar a dor como algo que a mulher como mãe deva fazer. Se há constantemente a referência ao

8 Outra categoria que se refere a uma experiência física e/ou emocional é sofrimento, que não foi, contudo, usada pelas mulheres entrevistadas. 
modo como o parto deve ser vivenciado, as jovens entrevistadas buscam reafirmar seus esforços para se ajustar a esses ideais e valores, desafiando assim os estigmas em torno da maternidade adolescente.

As histórias apresentadas neste artigo mostram um contexto social distinto das jovens canadenses e das mulheres brasileiras que tiveram filhos nas décadas de 1940 e 1950 estudadas por Martins (2005) e Almeida (1987). A visão da maternidade como um papel e um código a ser seguido de forma naturalizada, apontada por Martins e Almeida, não se coloca nos relatos de parto examinados neste artigo. Ambas as gerações entrevistadas tratam o evento como significativo subjetivamente, marcado pelo desejo e escolha por certo tipo de parto. As reações aos profissionais de saúde, mencionadas pelas mulheres mais velhas e mais jovens, sugerem que o papel de paciente em uma relação desigual com o obstetra é vivido com tensões, mesmo que nos últimos anos esse modelo de atendimento venha mudando.

As diferenças geracionais são, contudo, expressivas e refletem-se na forma como os partos são narrados: o maior ou menor detalhamento da história, o modo como os personagens são referidos e o espaço que ocupam na narrativa, o tipo de elemento dramático mencionado, a forma como as emoções estão presentes. A participação intensa dos maridos das mais jovens revela uma forma de conjugalidade que já surgia na década de 1980, quando Salem (2007) estudou o modelo igualitário do casal grávido. A presença de diálogos com obstetras ao longo de toda a narrativa mostra em ambos os grupos de mulheres a centralidade dessa relação na experiência do parto. O fato de os médicos serem nomeados pelas mulheres mais jovens indica uma relação mais pessoalizada, tentativa também de reduzir a assimetria entre eles (McCallum, 2007), se comparado às mais velhas. Igualmente importante é a referência aos hospitais - ao espaço físico dos quartos e centros cirúrgicos, às falas de enfermeiras, maqueiros e outros profissionais, revelando assim como o parto é vivenciado principalmente enquanto evento médico, mais do que familiar ou como experiência subjetiva e corporal da mulher. Não aparece nessas narrativas, mesmo entre as mais jovens, o destaque dado à vivência de um estado subjetivo mais intenso, como a ida à "partolândia" mencionada pelas entrevistadas de Carneiro (2015).

A extensão dos relatos das mais jovens, que relembram muitos diálogos, emoções e sensações físicas, também sugere a importância do evento em si do parto para elas, algo a ser planejado e vivenciado intensamente (Carneiro, 2015). 
Não acredito que as narrativas mais curtas das mulheres mais velhas sejam em função apenas de uma memória mais "apagada" por conta do tempo maior entre os partos e a sua rememoração, como argumentou Martins (2005) em seu estudo. Havia também entre elas um tipo de parto almejado, mas que muitas vezes não ocorria por conta de imprevistos diversos. A presença constante desses elementos inesperados nas histórias sugere que elas não buscavam controlar toda a situação como as mais novas. A maternidade era desejada, mas o parto era pouco significativo enquanto objeto de preocupação. Só surgia como questão depois de uma vivência traumática.

A estrutura comum das histórias remete a uma experiência de gênero em uma sociedade na qual o corpo, especialmente o feminino, é fortemente medicalizado. A dinâmica emocional presente - da calma inicial, a dor e tensão vinda de acontecimentos inesperados, ao alivio final - fala de sensações que são também corporais e realça o tom de superação das narrativas. As mulheres mais velhas superaram principalmente as imposições médicas, acontecidas de forma mais marcada. As mais jovens venceram as dores do parto bem como uma sensação mais ampla de falta de controle de si e da situação. Se a vivência do parto para elas implicou graus variados de perda de agência, por outro lado, colocar essa experiência em forma narrativa permite recuperá-la e destacá-la, como ressaltam Maynes, Pierce e Laslett (2008). Assim, nos relatos analisados, mesmo diante das relações de poder que atravessam o percurso da paciente mulher pelo sistema médico hospitalar, sobressai a ênfase em sua capacidade de suportar as dores do parto e/ou as imposições médicas, tornando-as histórias de superação.

\section{Referências}

ABU-LUGHOD, L. Shifting politics in Bedouin love poetry. In: LUTZ, C.; ABU-LUGHOD, L. (ed.). Language and the politics of emotion. Cambridge: Cambridge University Press, 1990. p. 24-45.

ABU-LUGHOD, L.; LUTZ, C. Introduction: emotion, discourse and the politics of everyday life. In: LUTZ, C.; ABU-LUGHOD, L. (ed.). Language and the politics of emotion. Cambridge: Cambridge University Press, 1990. p. 1-23.

ALMEIDA, M. I. M. de. Maternidade: um destino inevitável?. Rio de Janeiro: Campus, 1987. 
ARFUCH, L. O espaço biográfico: dilemas da subjetividade contemporânea. Rio de Janeiro: Ed. UERJ, 2010.

AURELIANO, W. de A. As pessoas que as doenças têm: entre o biológico e o biográfico. In: GONÇALVES, M. A.; MARQUES, R.; CARDOSO, V. Z. (org.). Etnobiografia: subjetivação e etnografia. Rio de Janeiro: 7 Letras, 2012. p. 239-260.

BRUNER, E. Experience and its expressions. In: TURNER, V. W.; BRUNER, E. M. (ed.). The anthropology of experience. Chicago: The University of Chicago Press, 1986. p. 3-30.

CARNEIRO, R. G. Cenas de parto e políticas do corpo. Rio de Janeiro: Editora Fiocruz, 2015.

CARSON, A. et al. A narrative analysis of the birth stories of early-age mothers. Sociology of Health \& Illness, v. 39, n. 6, p. 816-831, 2017.

CHAZAN, L. K. "Meio quilo de gente”: um estudo antropológico sobre ultrassom obstétrico. Rio de Janeiro: Editora Fiocruz, 2007.

COELHO, M. C. Narrativas da violência: a dimensão micropolítica das emoções. Mana, Rio de Janeiro, v. 16, n. 2, p. 265-285, 2010.

FOUCAULT, M. Vigiar e punir: história da violência nas prisões. Petrópolis: Vozes, 1997.

HALBWACHS, M. A memória coletiva. São Paulo: Vértice, 1990.

HIRSCH, O. O parto "natural" e "humanizado" na visão de mulheres de camadas médias e populares no Rio de Janeiro. Civitas, Porto Alegre, v. 15, n. 2, p. 229-249, 2015.

LE BRETON, D. As paixões ordinárias: antropologia das emoções. Petrópolis: Vozes, 2009.

MARTINS, A. P. V. Memórias maternas: experiências da maternidade na transição do parto doméstico para o parto hospitalar. História Oral, v. 8, n. 2, p. 61-76, 2005.

MAUSS, M. Ensaio sobre a dádiva: forma e razão da troca em sociedades arcaicas. In: MAUSS, M. Sociologia e antropologia: vol. II. São Paulo: EPU, 1974. p. 37-184.

MAUSS, M. A expressão obrigatória dos sentimentos. In: FIGUEIRA, S. A. (org.) Psicanálise e ciências sociais. Rio de Janeiro: Livraria Francisco Alves, 1981. p. 56-63.

MAYNES, M. J.; PIERCE, J.; LASLETT, B. Telling stories: the use of personal narratives in the social sciences and history. Ithaca: Cornell University Press, 2008.

MCCALLUM, C. Sem nome: pessoa como processo na dinâmica racial e de gênero brasileira. In: PINA CABRAL, J. de; VIEGAS, S. de M. (org.). Nomes: gênero, etnicidade e família. Lisboa: Almedina, 2007. p. 265-289. 
ORTNER, S. B. Anthropology and social theory: culture, power, and the acting subject. Durham: Duke University Press, 2007.

RABELO, M. et al. Experiência de doença e narrativa. Rio de Janeiro: Editora Fiocruz, 1999.

RABINOW, P.; ROSE, N. Biopower today. BioSocieties, v. 1, n. 2, p. 195-217, 2006.

REZENDE, C. B. Trust, gender and personhood in birth experiences in Rio de Janeiro, Brazil. Vibrant: Virtual Brazilian Anthropology, v. 14, n. 3, p. 58-71, 2017. Disponível em: http://www.vibrant.org.br/claudia-barcellos-rezende-trust-gender-and-personhood-in-birth-experiences-in-rio-de-janeiro-brazil/. Acesso em: 20 maio 2018.

RIESSMAN, C. K. Narrative analisys. London: Sage, 1993.

ROHDEN, F. Uma ciência da diferença: sexo e gênero na medicina da mulher. Rio de Janeiro: Editora Fiocruz, 2001.

ROSALDO, M. Toward an anthropology of self and feeling. In: SHWEDER, R. A.; LEVINE, R. A. (ed.). Culture theory: essays on mind, self, and emotion. Cambridge: Cambridge University Press, 1984. p. 137-157.

SALEM, T. O casal grávido: disposições e dilemas da parceria igualitária. Rio de Janeiro: Editora FGV, 2007.

SARTI, C. A. A dor, o indivíduo e a cultura. Saúde e Sociedade, v. 10, n. 1, p. 3-13, 2001.

SIMAS, R. Doulas e o movimento pela humanização do parto: poder, gênero e a retórica do controle das emoções. 2016. Dissertação (Mestrado em Antropologia) - Instituto de Ciências Humanas e Filosofia, Universidade Federal Fluminense, Niterói, 2016.

TORNQUIST, C. S. Parto e poder: o movimento pela humanização do parto no Brasil. 2004. Tese (Doutorado em Antropologia Social) - Centro de Filosofia e Ciências Humanas, Universidade Federal de Santa Cantarina, Florianópolis, 2004.

Recebido: 21/05/2018 Aceito: 05/02/2019 | Received:5/21/2018 Accepted: 2/5/2019 